\title{
A INDÚSTRIA FARMACÊUTICA E PSICANÁLISE DIANTE DA “EPIDEMIA DE DEPRESSÃO": RESPOSTAS POSSÍVEIS
}

\author{
Letícia Vier Machado ${ }^{1}$ \\ Universidade Federal de Santa Catarina, Florianópolis-SC, Brasil \\ Rodrigo Ramires Ferreira \\ Universidade Estadual de Maringá, Maringá-PR, Brasil
}

\begin{abstract}
RESUMO. O crescimento de diagnósticos de depressão verificado na atualidade vem acompanhado da ampliação do mercado da indústria farmacêutica, do comércio de antidepressivos e do fenômeno da medicalização da vida. O objetivo do estudo teórico é analisar os fatores que subjazem ao que o sociólogo Philippe Pignarre denominou de "epidemia de depressão", fenômeno complexo que não deve ser reduzido a fatores unicamente biológicos ou sociais, mas carrega em seu bojo uma economia de fármacos em expansão. Serão levantados alguns dados sobre as estratégias da indústria farmacêutica para ganhar o terreno em expansão dos diagnósticos e elevar seus medicamentos ao patamar de produtos a serem consumidos, tornando-se um dos setores mais rentáveis do mundo. Em seguida, questiona-se o estatuto da psicanálise na sociedade medicalizada, a partir das críticas que esta tem recebido nas últimas décadas, sobretudo na França, revelando a incapacidade do sujeito contemporâneo de expressar em palavras o sofrimento que o acomete.
\end{abstract}

Palavras-chave: Medicalização; depressão; psicanálise.

\section{THE PHARMACEUTICAL INDUSTRY AND PSYCHOANALYSIS FACING THE "EPIDEMIC OF DEPRESSION": POSSIBLE ANSWERS}

\begin{abstract}
The increase of depression's diagnoses nowadays is related to the expansion of the pharmaceutical industry market, and also to the trade of antidepressant drugs and to life's medicalization phenomenon. The aim of this theoretical study is to analyze the factors that underlie what Philippe Pignarre called "epidemic of depression", a complex phenomenon that should not be reduced to biological or social factors, but it carries within it a booming drug economy. Some data will be collected on the strategies of the pharmaceutical industry to gain ground on expansion of diagnostics in order to raise their drugs on a level of products to be consumed, becoming one of the most profitable sectors of the world. Then, we question the status of psychoanalysis in a medicalized society, analyzing the critics that the theory has received in recent decades, especially in France, revealing the inability of the contemporary subject to express in words his suffering.
\end{abstract}

Key words: Medicalization; depression; psychoanalysis.

\section{LA INDUSTRIA FARMACÉUTICA Y PSICOANÁLISIS FRENTE A LA "EPIDEMIA DE DEPRESION": POSSIBLES RESPUESTAS}

RESUMEN. El crecimiento de los diagnósticos de depresión en la actualidad viene acompañado de la expansión del mercado de la industria farmacéutica, del comercio de los antidepresivos y del fenómeno de la medicalización de la vida. El objetivo de este estudio teórico es analizar los factores que subyacen a lo que el sociólogo Philippe Pignarre denominó de "epidemia de depresión", fenómeno complejo que no se debe reducir a factores únicamente biológicos o sociales, sino que lleva en sí una economía de los fármacos en expansión. Se recogieron algunos datos acerca de las estrategias de la industria farmacéutica para ganar el terreno en expansión de los diagnósticos y elevar sus medicamentos al nivel de productos que serán consumidos,

1 Endereço para correspondência: Rua Joaquim Nabuco, 120, ap. 62, Zona 04, CEP 87.014-100, Maringá-PR. Email: leticiaviermachado@gmail.com 
convirtiéndose en uno de los sectores más rentables del mundo. A continuación, se discute el estatuto del psicoanálisis en la sociedad medicalizada, a partir de las críticas que ha recibido en las últimas décadas, sobre todo en Francia, revelando la incapacidad del sujeto contemporáneo para expresar en palabras su sufrimiento.

Palabras clave: Medicalización; depresión; psicoanálisis.

"Drogar-se, legalmente, é uma marca de nossa época."

(Brum, 2013)

A Organização Mundial da Saúde (OMS, 2001) anunciou que a depressão será nos próximos anos um dos grandes problemas que a saúde pública terá que enfrentar. Já percebemos no cotidiano o crescimento de diagnósticos e de autodiagnósticos de depressão que nos rodeiam, somados ao crescente consumo de psicofármacos, entre eles, o de antidepressivos.

É inegável a participação da indústria farmacêutica, um dos setores econômicos mais rentáveis do mundo, na expansão desse fenômeno. Aliada à psiquiatria moderna, a indústria farmacêutica busca prevenir as "anormalidades", principalmente após a nova forma de pensar os transtornos psiquiátricos a partir do lançamento da terceira edição do Manual Diagnóstico e Estatístico de Transtornos Mentais (DSM III), em 1980.

Assistimos ao processo de medicalização da vida, em que problemas exteriores ao corpo biológico são transformados em distúrbios, transtornos e disfunções biológicas passíveis de tratamento medicamentoso, entre os quais o carro-chefe é a depressão. A depressão, mais do que um transtorno de humor, passa a ser um modo de subjetivação. Em outros termos, ser "deprimido" é uma identidade, um modo de produzir sujeitos medicalizados que se definem a partir do que os acomete.

Nesse contexto, qualquer reflexão sobre si fica excluída ou se torna obsoleta, uma vez que remete ao sofrimento psíquico e à interioridade do sujeito. Esquece-se, por exemplo, que a psicanálise, acessando $\mathrm{o}$ inconsciente $\mathrm{e}$ tomando a depressão como um sintoma do sofrimento psíquico em suas diferentes roupagens na atualidade, é capaz de resgatar essa interioridade e acessar a verdade do sujeito através da fala.

Não obstante, inserida em um debate científico crescente, pautado exclusivamente na objetividade, no molde das chamadas ciências duras, a psicanálise parece perder espaço ante a ocupação silenciosa e epidêmica do terreno da depressão pelos psicofármacos.

A partir dessas considerações, o intuito dessa discussão teórica é trazer a lume dados da indústria farmacêutica que permitam visualizar seu imbricamento com o crescimento de diagnósticos de depressão, que, como afirma Philippe Pignarre, configura-se como uma verdadeira epidemia do transtorno. Em seguida, procurou-se discutir as repercussões desse fenômeno na prática clínica psicanalítica, que vem enfrentando fortes críticas nos últimos anos.

\section{INDÚSTRIA FARMACÊUTICA, MEDICALIZAÇÃO E O MERCADO DAS DOENÇAS}

O fenômeno da medicalização da vida é latente na sociedade contemporânea. Em seu bojo está o crescimento acelerado da indústria farmacêutica, alocando a produção de medicamentos como o segundo setor mais rentável do mundo, como também o segundo em concentração de capital, competindo apenas com grandes bancos internacionais (Santos \& Farias, 2010; St-Onge citado por Lorenzo \& Garrafa, 2010).

Traçando um breve panorama numérico dessa maquinaria, que se configura hoje como um conjunto de oligopólios detentores de grande concentração de capital, ressalta-se o aumento significativo do consumo de certos fármacos. Denominados metaforicamente por Camargo Jr. (2010, p. 39) de medicamentos blockbusters, assim como os filmes, fazem sucesso e se disseminam facilmente entre o público.

Dentre estes, situam-se no topo da pirâmide os psicofármacos, aliados à multiplicação de diagnósticos e ao aparecimento constante de novas síndromes no campo da psiquiatria contemporânea, para as quais são cada vez mais indicados os fármacos do humor, com a promessa da correção dos estados psíquicos supostamente desviantes. Neste sentido, os antidepressivos detêm o terceiro lugar entre os fármacos mais vendidos no mundo: 
Somente nos Estados Unidos - onde os antidepressivos foram durante alguns anos o tipo de medicamento mais consumido - o volume de vendas desses fármacos foi, em 2004, de 10 milhões de dólares, mais da metade das vendas mundiais (NICHM Foundation, 2002; Lewis et al., 2005, citada por Hernáez, 2010, p. 114).

Assim, não é por acaso que o setor farmacêutico tem sido elencado como "um dos mais rentáveis dos Estados Unidos nos últimos cinquenta anos" (Appaix, 2011, p. 27). Ainda na categoria dos psicofármacos, ao lado do mercado dos antidepressivos, os antipsicóticos também ocupam as primeiras posições de venda. De acordo com Olivier Appaix (2011), 1.100 pessoas, entre adultos e crianças, integram diariamente a lista para receber ajuda financeira federal para comprar medicamentos antipsicóticos.

A indústria farmacêutica busca elevar seus medicamentos a um patamar de produto a ser consumido, usando de dados estatísticos por ela patrocinados, muitas vezes eticamente questionáveis, para balizar sua eficácia (Camargo Jr., 2010). Além destes fatores, diagnósticos dos ditos transtornos mentais na infância, como transtorno de déficit de atenção e hiperatividade (TDAH) e autismo, aumentaram sobremaneira, tendo efeitos proporcionais no mercado farmacêutico, por meio da indicação de psicofármacos que regulem condutas diagnosticadas como de TDAH, por exemplo:

\begin{abstract}
Nos Estados Unidos, desde o começo dos anos 2000, um milhão de crianças foram diagnosticadas com transtorno bipolar. Abaixo dos dezesseis mil em 1992, o número de autistas entre seis e vinte e dois anos passou para 293 mil em 2008, ou para 338 mil, se incluídas as crianças de três a seis anos.... (Appaix, 2011, p. 26).
\end{abstract}

Também no Brasil, o segundo maior consumidor de metilfenidato - usado principalmente em crianças diagnosticadas com TDAH - o Boletim de Farmacoepidemiologia da Agência Nacional de Vigilância Sanitária aponta um crescimento de $75 \%$ no consumo deste medicamento entre 2009 e 2011. Dito de outro modo, se consideradas as variações no consumo entre 2001 e 2011, o aumento passa dos $1.600 \%$ (Correia Filho \& Oliveira, 2011, citados por Ferreira, 2013).

Ademais, o mercado farmacêutico não se esgota nos medicamentos. Médicos psiquiatras norte-americanos são financiados pelos laboratórios farmacêuticos para proferir conferências sobre seus medicamentos. Cursos para diagnosticar transtornos mentais são ministrados, revistas médicas são financiadas para a publicação de resultados favoráveis aos medicamentos e empresas de exames médicos crescem desenfreadamente nos Estados Unidos com o mercado de diagnósticos de transtornos mentais por meio de imagens cerebrais (Appaix, 2011; Hernáez, 2010). A empresa norteamericana CereScan, por exemplo, integra essa lista, prevendo a abertura de vinte novos centros nos Estados Unidos (Appaix, 2011).

Além disso, esse quadro conta ainda com o fator publicitário. Hernáez (2010) resume algumas das principais estratégias publicitárias das quais a indústria farmacêutica faz uso, entre as quais figuram a publicidade direcionada aos médicos em troca de "recompensas" (p. 125) e a publicidade direta e indireta ao consumidor como é o caso, por exemplo, dos Estados Unidos, onde a publicidade muitas vezes aparece fragmentada, omitindo resultados indesejáveis ou efeitos colaterais dos medicamentos divulgados. Sobre isto afirmam Santos \& Farias (2010, p. 284):

A propaganda de medicamentos no Brasil é regulamentada pelas Leis 6360/1976 e 9294/1996, pelos Decretos 79094/1977, 2018/1996 e pelo Código de Defesa do Consumidor, Lei 8078/1990, bem como Portarias específicas. Para o público leigo é permitida apenas a promoção de medicamentos de venda isenta de prescrição. A promoção de medicamentos de venda sob prescrição é permitida apenas para profissionais de saúde.

É válido lembrar que a indústria farmacêutica adquiriu novos contornos a partir das transformações econômicas ocorridas no período que se seguiu à Segunda Guerra Mundial, quando o foco na produção industrial cedeu lugar ao saber científico e às pesquisas tecnológicas.

No plano econômico, na década de 1960 e meados da década de 1970 a indústria farmacêutica foi marcada pelo desenvolvimento 
de pesquisas tecnológicas, sendo que, nesse período, as empresas ainda eram majoritariamente nacionais (Angell citado por Santos \& Farias, 2010). Ainda na década de 1970, uma importante transição se efetua com a disseminação dos medicamentos genéricos e consequente diminuição dos lucros das grandes empresas farmacêuticas, além do surgimento da biotecnologia, que na década seguinte desembocaria no surgimento crescente de novos medicamentos. Estes novos medicamentos trazem uma grande promessa advinda da indústria farmacêutica: acabar com os sintomas de forma mais rápida e eficaz, deixando-se de lado outros meios terapêuticos.

Assim, na década de 1980 se inicia uma corrida por "medicamentos inovadores", culminando no surgimento do antidepressivo fluoxetina, na Bélgica, no ano de 1986 (Angell citado por Santos \& Farias, 2010; Hernáez, 2010) resultante do aprimoramento dos antidepressivos que surgiram já na década de 1960 (Preciado, 2008). A fluoxetina, popularizada nos Estados Unidos sob o nome de Prozac, inaugura toda uma geração de psicotrópicos, mas também da produção de subjetividades que marcariam a chamada "geração Prozac".

Tamanho foi o impacto da fluoxetina que ela recebeu inúmeros codinomes, como: "A cultura das drogas legais" (Rimer, 1993); "A cápsula da fuga" (Bracewell, 1993); "A nova cosmética psicofarmacológica" (Kramer, 1993); "A pílula da personalidade" (Toufexis, 1993); "A pílula das pílulas" (Nuland, 1994); "A geração Prozac" (Grant, 1994)" (citados por Hernáez, 2010, p. 112). Além disso, a fluoxetina, mais precisamente o Prozac $®$, ocasionou uma verdadeira revolução na indústria farmacêutica, elevando os antidepressivos à condição de um dos medicamentos mais consumidos nos Estados Unidos nos últimos dez anos.

A partir de então, inicia-se outra corrida, não mais por "medicamentos inovadores", mas por doenças, síndromes e transtornos inovadores. À beira do novo milênio, na década de 1990, cresceram os investimentos em pesquisas na indústria de cosméticos e dermatologia. Medicamentos para o emagrecimento e perda do apetite passaram a ser comercializados, assim como o metilfenidato ou Ritalina $\AA$, para 0 tratamento do Transtorno de Déficit de Atenção e Hiperatividade, e os psicotrópicos para a depressão infantil (Preciado, 2008).

\section{A "EPIDEMIA" DE DEPRESSÃO}

Malgrado o aparecimento das novas síndromes, a depressão permanece atuando como um dos principais motores da maquinaria farmacêutica. Esse fenômeno foi largamente explorado por Philippe Pignarre, sociólogo francês que, depois de ter trabalhado no ramo farmacêutico, passou a explorar as contradições da indústria de medicamentos. Para o autor, o "surto" de depressão a que assistimos se configura como uma verdadeira epidemia: não é por acaso que a depressão é hoje a quarta causa mundial de incapacidade, devendo passar à segunda posição nos próximos vinte e cinco anos (Pignarre, 2012).

No dicionário Michaelis da língua portuguesa, a palavra epidemia é definida como: "1. Doença que ataca ao mesmo tempo muitas pessoas da mesma terra ou região; 2. Ideias, sistemas ou coisas que se difundem com abundância e rapidez, dominando os espíritos ou os costumes" (Michaelis, 1998, p. 831). Dito de outro modo, uma das características da epidemia é a relação que se estabelece entre as grandezas tempo e quantidade.

Neste sentido, Pignarre (2012) afirma que na França o número de pessoas deprimidas multiplicou-se por sete entre as décadas de 1970 e 1990. De acordo com um estudo realizado em 2005 pelo Inpes (Institut National de prévention et éducation pour la santé),

$8 \%$ dos franceses de 15 a 75 anos (aproximadamente 3 milhões de pessoas) viveram uma depressão nos doze meses anteriores à pesquisa; $19 \%$ dos franceses de 15 a 75 anos (aproximadamente 8 milhões de pessoas) viveram ou viverão uma depressão na vida (Inpes, 2007, p.7, tradução nossa).

Em paralelo, o Ministério da Saúde divulga que atualmente no Brasil são aproximadamente 10 milhões de quadros depressivos registrados (Ministério da Saúde, 2013). Neste quadro, a questão latente é como a depressão se tornou uma das síndromes ou doenças mais diagnosticadas das últimas décadas. Para Pignarre (2012), algumas justificativas comumente encontradas para responder a esse questionamento são insuficientes, como, por exemplo, a tese sociológica de que vivemos em 
uma sociedade produtora de infelicidades, ou seja, numa sociedade "depressogênica".

Apesar de sociólogos como Zygmunt Bauman (1998) já terem teorizado largamente sobre os efeitos da sociedade líquida sobre os indivíduos, demonstrando como estes não podem permanecer incólumes diante da crise da modernidade, Pignarre (2012) atenta para o teor crítico e não esclarecedor dessa tese. Em outros termos, falar de uma sociedade produtora de mal-estares é mais uma crítica social do que uma explicação dos reais motivos da epidemia depressiva.

Do mesmo modo, parecem insuficientes para Pignarre (2012) a tese das predisposições genéticas e a tese psíquica. A primeira vai de encontro à tese sociológica, afirmando que a depressão teria sempre existido, mesmo na ausência de instrumentos para diagnosticá-la. A predisposição indica um fator biológico que se manifestaria combinado com eventos externos. Já a segunda, ao contrário da predisposição genética, aloca a depressão na esfera privada, como consequência de uma estrutura psíquica.

No Brasil, o Ministério da Saúde, na campanha nacional "Uso Racional de Medicamentos", elenca a depressão como um dos temas-chave. Distribui suas causas entre as três teses supracitadas (a sociológica, a biológica e a psicológica) (Ministério da Saúde, 2011).

Independentemente da justificativa adotada, em nenhuma das três explicações o crescimento da indústria farmacêutica (conforme exposto anteriormente) e do mercado dos psicotrópicos aparece como fator que contribui para o aumento da depressão e medicalização contemporâneas. Neste sentido, organizamos a teoria de Pignarre (2012) de modo a contemplar a análise da epidemia de depressão em três frentes: a econômica, a política e a psicológica.

$\mathrm{Na}$ perspectiva econômica, é possível afirmar que, além de uma epidemia, síndrome ou doença, a depressão é antes de tudo um nicho de mercado. Pignarre (2012) retoma os princípios da economia clássica, salientando que o funcionamento de um mercado depende, primeiramente, da criação de ofertas. Cabe lembrar que na década de 1950, no contexto do surgimento da imipramina, antidepressivo anterior à chamada "geração Prozac" supracitada, os laboratórios farmacêuticos não financiaram o desenvolvimento do fármaco por considerar insignificante o "mercado da depressão" (Pignarre, 2012, p. 54). Em outros termos, partia-se do princípio de que para vender a ideia da depressão é preciso antes criar consumidores convencidos a comprá-la.

Tomemos um exemplo de Pignarre (2012) que permite visualizar a criação de um mercado específico de consumidores de antidepressivos. O autor retoma a estratégia do laboratório dinamarquês Lundbeck, que para criar o mercado da depressão masculina, em oposição à depressão feminina, financiou as pesquisas de renomados psiquiatras, que legitimaram os sintomas da depressão masculina por meio do discurso científico em congressos e eventos internacionais, e a abordaram em nível de problema de saúde pública. Isso não significa que os pesquisadores tenham defendido um discurso do qual não eram adeptos, ou que o laboratório os corrompeu, mas apenas que Lundbeck forneceu-lhes os meios financeiros para defender a tese da existência de uma depressão especificamente masculina (Pignarre, 2012).

No mesmo sentido, um exemplo mais próximo e generalista pode ser tomado em relação a outros medicamentos. A esclerose múltipla, doença que atinge aproximadamente trinta mil brasileiros, foi alvo de campanhas de sensibilização apoiadas por grandes indústrias farmacêuticas, e o medicamento para seu tratamento, o Betaferon/Betaseron $\AA$, da Bayer, consta no relatório anual da companhia como o mais vendido do ano de 2011 , totalizando um lucro de 1,117 milhões de euros (Bayer, 2011).

A partir desses exemplos, constata-se a possibilidade e a potencialidade da indústria farmacêutica para criar o que Pignarre (2012) denominou de nichos de consumidores para um fármaco específico, investindo no público-alvo. Ademais, a economia da depressão também investe em publicidade e em conhecimento científico.

Em primeiro lugar, o fator publicitário: no plano teórico, a publicidade opera no nível do desejo. Vivemos sob o imperativo do consumo, em que o desejo é captado e transformado em mercadoria. No plano prático, propagandas e campanhas contribuem para o crescimento da epidemia de depressão. Neste sentido afirma Pignarre (2012, p. 98, tradução nossa):

$\mathrm{Na}$ Grã-Bretanha, as associações de psiquiatras e de médicos generalistas organizaram, de 1991 a 1995, a Defeat Depression Campaign. Esta comportava 
duas frentes: uma em direção aos médicos generalistas e outra em direção do grande público. Graças a ela, o consumo de antidepressivos aumentou $33 \%$. Nos Estados-Unidos, uma campanha acontece a cada ano desde 1991: o National Depression Screening Day, que propõe uma testagem individual. Em 1996, 18.000 profissionais da saúde participaram do evento.

Do mesmo modo, como afirma Pignarre (2012), na França a imprensa feminina dedica pelo menos um dossiê de revistas por mês à temática da depressão. Também no Brasil o tema tem ganhado espaço nos meios de comunicação, sobretudo na televisão, com a criação de quadros televisivos em horários disputados, ministrados por médicos que explicam os efeitos "positivos" dos antidepressivos e as transformações geradas por eles na vida do paciente.

A Rede Globo de Televisão criou recentemente um quadro no programa "Fantástico", denominado "Os males da alma". A edição de inauguração teve como tema a depressão, defendendo a tese de que a psicoterapia pode auxiliar, mas não é reembolsada pelos planos de saúde e a fila para o acesso ao psicólogo na rede pública é quase inacessível. Por outro lado, os psicotrópicos são acessíveis e de rápido resultado. A reportagem está disponível em: < http://g1.globo.com/fantastico/videos/t/edicoes/v/ depressao-atinge-350-milhoes-de-pessoas-nomundo/2411751/>.

O conhecimento científico, por sua vez, pode ser compreendido em relação ao fator publicitário. Partindo da compreensão de que a divulgação dos resultados de estudos clínicos era um forte veículo publicitário, a própria indústria farmacêutica, para criar o "mercado da depressão" que considerava inexistente na década de 1950, começou a patrocinar os estudos clínicos de antidepressivos (Pignarre, 2012).

Do ponto de vista político, ressaltamos o papel das organizações, intimamente relacionadas à economia e ao conhecimento científico, para a contaminação da epidemia de depressão. Com efeito, a mesma organização que anunciou ser a depressão o "mal do século" capacitou médicos generalistas para detectá-la em uma consulta de duração máxima de quinze minutos.
Assim, com o uso do Manual Diagnóstico e Estatístico de Transtornos Mentais (DSM) como instrumento diagnóstico, é possível classificar um caso como de depressão se presentes cinco sintomas de nove por mais de duas semanas. No mesmo sentido, a Organização Mundial da Saúde (OMS), em parceria com a indústria farmacêutica, divulgou a importância das psicopatologias e a formação deficiente dos médicos nessa área para, em seguida, engendrar programas de formação rápida e capacitar os médicos a detectar os deprimidos (Pignarre, 2012).

Um dos problemas dessa metodologia fastfood é que o diagnóstico centrado nos sintomas de ansiedade, fadiga, insônia e outros, exclui do quadro todos os fatores sociais envolvidos na instalação do suposto quadro depressivo. Sem recair no sociologismo, como alerta Pignarre (2012), é inegável a participação dos meios de comunicação e da mídia no humor depressivo daqueles que não correspondem ao ideal de beleza de nossa sociedade hedonista, como observa Rodrigues (2003). Ou ainda, como exemplifica Pignarre (2012), medicar um quadro depressivo provocado por constantes episódios de assédio moral no trabalho é certamente um equívoco, já que não resulta em nenhuma modificação das condições de trabalho impostas ao medicado.

Por fim, o aspecto psicológico da depressão diz respeito às vantagens, ou ainda - no vocabulário psicanalítico - à resistência gerada pelo benefício secundário que ela proporciona ao deprimido. Em outras palavras, para justificar comportamentos, é mais legítimo assumir-se "deprimido" do que engendrar reflexões sobre o modo de vida contemporâneo, sobre a falta ou o excesso de felicidade que a sociedade exige de seus membros, no imperativo da necessidade do "gozar a qualquer preço", nos termos do psicanalista Charles Melman (2003).

No mesmo sentido, para o filósofo lan Hacking (2000, citado por Sanches 2010, p. 23), obter um diagnóstico para justificar comportamentos é uma necessidade de pertencimento identitário. Isto está relacionado ao sofrimento do sujeito, que busca uma solução na esfera biológica e farmacêutica.

Sendo assim, a depressão, ao lado do rol de outros transtornos mentais que demandam um espaço na $5^{a}$ edição do Manual Diagnóstico e Estatístico de Transtornos Mentais (DSM-V), a ser lançada em breve, tornou-se uma identidade 
requisitada, um verdadeiro modo de subjetivação. O DSM traz a cada nova edição, um grande número de novos transtornos, outros velhos que ganham novas roupagens e limites para sua identificação cada vez mais elásticos (Ferreira, 2013). Para Pignarre (2012), "nós fabricamos a depressão e, simultaneamente, a depressão nos fabrica" (p. 34, tradução nossa).

Desde a década de 1960 a indústria farmacêutica passou a adentrar a esfera dos saberes correlatos aos ditos transtornos mentais através de estratégias midiáticas e de produção científica, nos moldes da ciência moderna, formal, e de mãos dadas com a psiquiatria, suprime outras possibilidades terapêuticas.

A psicanálise encontra-se neste campo de terapêuticas alternativas à medicação suprimidas pela indústria farmacêutica. Oferece uma escuta através da palavra para a elaboração do mal-estar, do sofrimento do sujeito. A psicanálise então "se compreende como uma experiência do sujeito onde os conceitos servem para articular um fenômeno que não é da ordem das ciências naturais ou formais" (Perez, 2009, p. 1211).

\section{CRISE DA PALAVRA, CRISE DA PSICANÁLISE?}

\author{
"Nossa sociedade parece ter \\ definido um modo privilegiado de \\ sofrer, um modo medicalizado de \\ administrar os fracassos e as \\ angústias" \\ (Caponi, 2010, p. 142).
}

Ao enunciar o grande golpe narcísico que a humanidade teria sofrido com o surgimento da Psicanálise, indicando a partir do inconsciente não ser o homem senhor de si mesmo, Freud já antecipava argumentos que serviriam para rebater aqueles que questionaram a legitimidade dessa ciência (Freud, 1917/1976).

Com efeito, Freud não tardou a perceber que a Psicanálise não poderia conquistar um lugar no paradigma científico dominante, uma vez que sua criação não pertencia a essa ordem, não era causalística, tampouco objetiva, mas de outra ordem bem diferente: seus resultados não são mensuráveis; seu contexto é o da experiência; seu objeto, o sujeito na relação com o próprio desejo (Perez, 2009).

Essa relação é capaz de deslocar o foco do sintoma que chega à clínica com o nome "depressão" e investir no acesso à verdade subjetiva, fazendo emergir o mal-estar na falta. Assim, ao pressupor um sujeito da falta e do desejo, que se faz através da linguagem na relação com o outro, a psicanálise singulariza o sofrimento psíquico.

Acontece que no contexto do paradigma científico dominante não resta espaço à singularidade: é preciso que o humano seja previsível, tratável e objetivo. Por não se enquadrar no modelo de ciência almejado, resistências e preconceitos contra a Psicanálise têm proliferado desde sua criação, no início do século $X X$, por Sigmund Freud.

Atualmente, Élisabeth Roudinesco, célebre historiadora da Psicanálise, tem participado de debates recentes em defesa dessa ciência contra os ataques que esta tem recebido, sobretudo na França, após o lançamento em 2005 do polêmico "Livro negro da psicanálise: viver e pensar melhor sem Freud", organizado por Catherine Meyer, e as recentes publicações de Michel Onfray, sobretudo as críticas à Psicanálise expostas no recente Le crépuscule d'un idole (Onfray, 2010).

Diante dessa suposta crise e da proliferação do ódio a Freud, Roudinesco (2010) argumenta: Freud, com a Psicanálise, trouxe à tona a intolerável revolução do íntimo e da intimidade. Com ela a humanidade teve que enfrentar a existência do inconsciente, admitindo a presença de um "estranho interior", de uma sexualidade infantil, de uma sexualidade feminina. Mais além: a psicanálise ressignificou o uso da palavra. Deu voz aos asilados, aos autistas, às histéricas do tempo de Freud e nomeou as angústias próprias ao humano (Roudinesco, 2010).

Posteriormente, com a revolução farmacológica que se seguiu à Segunda Guerra Mundial, culminando na revolução dos psicotrópicos, a Psicanálise passou a dividir espaço com as instituições asilares e, nelas, com o tratamento medicamentoso. $O$ terreno das psicoses, ainda não suficientemente explorado pela Psicanálise, é ocupado então pelos fármacos antipsicóticos.

Não obstante, a relação da psicanálise com a psiquiatria era ainda harmoniosa nas duas primeiras edições do Manual Estatístico e Diagnóstico de Transtorno Mental (DSM), que trazia descritores de transtornos de dois tipos: orgânicos e não orgânicos, com forte influência psicanalítica; mas a partir da tecnologia aplicada aos estudos de medicamentos modernos e 
"eficazes", que culminaram na publicação da terceira edição do DSM, a Psicanálise perde terreno, pois transtornos não orgânicos passaram a ser descritos numa base inteiramente orgânica. Para Russo e Venâncio (2006), "transtornos antes passíveis de um tratamento diferenciado - psicológico transformaram-se em distúrbios que, definidos em termos estritamente médicos, deveriam ser tratados como qualquer outra doença, isto é, medicamente" (p. 69).

Segundo Roudinesco (2010), os fármacos antipsicóticos representaram um progresso no tratamento das psicoses, mas não para as neuroses, tampouco para a depressão; entretanto, como salienta a autora, até mesmo nos quadros psicóticos é necessária certa dose de palavras.

Ocorre que nesse sentido, pesa o fator econômico, já que as psicoterapias, via de regra, não são reembolsadas pelos planos de saúde, fazendo com que o tratamento farmacológico (prescrito por psiquiatras e médicos generalistas) seja, aparentemente, menos custoso.

Por outro lado, no campo das neuroses o advento dos antidepressivos "poupa" a psicanálise de suas teorias sobre 0 funcionamento neurótico. Nada mais precisa ser explicado, mas apenas tratado e categorizado: eliminando a divisão entre neuroses e psicoses nodal para a psicanálise -, e classificando os transtornos em etiquetas passíveis de tratamento medicamentoso, os psicotrópicos minam o terreno da psicanálise.

Nos termos de Pignarre (2012), "os antidepressivos são a psicoterapia concentrada e industrializada" (p. 125). O autor acrescenta que os primeiros ainda detêm uma leve vantagem em relação à segunda, já que podem ocupar o lugar da psicoterapia e substituí-la, pois, enquanto os testes clínicos possibilitam mensurar a eficácia de um antidepressivo comparando-o com o grupo-controle, para o qual um placebo é administrado, é impossível mensurar objetivamente a eficácia de uma psicoterapia psicanalítica (Pignarre, 2012).

Aliás, não é a primeira vez que a Psicanálise perde terreno por conta da ausência de objetividade mensurável e da suposta cientificidade. Freud sempre se preocupou em defender a cientificidade da psicanálise, resistindo mesmo a modificações no enquadre do método psicanalítico a fim de consolidá-lo.
No Brasil, como repercussão de um movimento antipsicanalítico iniciado na França na última década, órgãos financiados pelo Governo que tratavam transtornos do espectro autista pelo método psicanalítico foram descredenciados, tendo seu financiamento suspenso, sob o argumento de que a Psicanálise não tem seu teor científico comprovado se comparada às terapias cognitivocomportamentais. Entre esses órgãos inclui-se o CRIA - Centro de Referência da Infância e da Adolescência -, de São Paulo, de excelência reconhecida entre os profissionais da saúde mental (Instituto Sedes Sapientiae, 2013).

Em face de tais eventos, é inegável a correlação entre estes e o crescimento de diagnósticos de autismo constatados por Appaix (2011), em que o número de autistas de até 22 anos de idade passou de 16 mil em 1992 para 338 mil em 2008. Afinal, com o aumento de diagnósticos, aumenta-se a atuação médica e a necessidade de soluções rápidas, objetivas, que não considerem as subjetividades em questão, mas o número de corpos atingidos e passíveis de correção.

De maneira análoga, o crescente diagnóstico de depressão enuncia algo sobre nós, sobre o sujeito contemporâneo, que difere do sujeito da psicanálise. Se este, gestado no bojo da cultura ocidental, é o sujeito intimista, singular, dotado de um inconsciente, de uma lei moral e de uma culpabilidade construídas a partir do Complexo de Édipo (Roudinesco, 2003), o sujeito contemporâneo medicalizado, em contrapartida, tem sua singularidade aniquilada em prol de um modo de existir universalizado em que qualquer experiência vivenciada é passível de cura, de correção medicamentosa, poupando o sujeito de se confrontar com suas frustrações de não ser o humano onipotente que a modernidade havia prometido. Em outros termos, a psicanálise incomoda porque, ao desafiar a onipotência do sujeito, mostra-lhe que ele nada sabe sobre si.

Nos dizeres de Pignarre (2012), enquanto a psicoterapia e, sobretudo, a psicanálise, remetem à verdade do sujeito, à intimidade, os psicotrópicos, por meio da explicação biológica da depressão, estão em vantagem quando desculpabilizam o sujeito de seu estado psíquico. Assim, eliminando qualquer tipo de escuta singular e de singularidade do humano, derivada da experiência ou da história individual, os antidepressivos incluem todo ser humano 
numa grande categoria de universalidade, cujo denominador comum é a existência de um corpo mental semelhante que por isso deverá ser tratado uniformemente.

Destarte, as causas e conteúdos do sofrimento já não interessam mais. $A$ psicoterapia é, doravante, secundária e coadjuvante, deixando espaço para a nanotecnologia farmacológica e, descredenciada, transforma-se num mero conjunto de conselhos de bom senso (Pignarre, 2012).

Se Freud e a psicanálise deram nome e significado ao sofrimento através da palavra, a medicalização contemporânea abafou as vozes, porque não suportamos mais quem somos, e mais além, não suportando mais admitir angústias e fracassos nós nos deprimimos. Por fim, arriscamos dizer que não é a psicanálise que está em crise, mas o sujeito por ela enunciado. Afinal, perpetuar uma escuta psicanalítica do sofrimento humano exige questionar-se constantemente, porque a evolução mesmo da psicanálise é movida por perguntas. De modo análogo, admitir em si um sofrimento instiga perguntas, e responder a estas com etiquetas e medicamentos é calar um estranho que a qualquer momento virá à tona.

\section{CONSIDERAÇÕES FINAIS}

Não defendemos a tese de que a depressão é um transtorno inexistente. $O$ que inquieta $e$ motiva esse estudo, e deve também inquietar o leitor, é o caráter epidêmico que esse "mal" adquiriu: ocupou nosso cotidiano de tal maneira que não há mais espaço para sentir, para sofrer e elaborar perdas, insucessos, lutos.

A indústria farmacêutica, por sua vez, assume um papel importante na divulgação do transtorno, no aumento de diagnósticos e do tratamento exclusivamente medicamentoso da depressão. A medicalização da vida é um dos fatores latentes que subjazem ao consumo desenfreado de antidepressivos, muitas vezes reembolsados e aparentemente "menos custosos" que o tratamento psicoterápico.

Por fim, é preciso reconhecer que, diante desse quadro, a psicanálise enquanto tratamento pela palavra perde terreno. Por ser questionada em sua "objetividade científica" e, mais profundamente, por trazer a lume conteúdos insuportáveis para o homem contemporâneo, ela precisa reinventar sua prática a cada dia, de modo a provocar, ainda que timidamente, pequenas revoluções do íntimo drogado e adormecido.

\section{REFERÊNCIAS}

American Psychiatric Association (2013) DSM-V development. Arlington, VA: Author. Recuperado em: 21 fev. 2013 de: <http://www.dsm5.org>.

Appaix, O. (2011, dezembro). O florescente mercado das "desordens psicológicas". In Le Monde Diplomatique Brasil, (pp. 26-27). Recuperado em 07 janeiro de 2012, de http://www.diplomatique.org.br/artigo.php?id=1067.

Bauman, Z. (1998). O mal-estar da pós-modernidade. Rio de Janeiro: Jorge Zahar.

Bayer. (2011). Principais produtos comercializados pela Bayer HealthCare em 2011, em todo o mundo. Recuperado em 21 de março de 2012, de http://www.bayerhealthcare.com.br/empresa/produ tos/index.php

Brum, E. (2013). O doping das crianças. Recuperado em 21 de março de 2013, de http://revistaepoca.globo.com/Sociedade/elianebrum/noticia/2013/02/o-doping-das-criancas.html

Camargo Jr., K. R. de. (2010). A economia política da produção e difusão do conhecimento biomédico. In S. Caponi (org.). Medicalização da vida: ética, saúde pública e indústria farmacêutica (pp. 3648). Palhoça: Unisul.

Caponi, S. (2010) O diagnóstico de depressão, a "petit biologie" e os modos de subjetivação. In S. Caponi (Org.). Medicalização da vida: ética, saúde pública e indústria farmacêutica (pp. 135-143). Palhoça: Unisul.

DSM-III (1980). Manual diagnóstico e estatístico de transtornos mentais. Porto Alegre: Artes Médicas.

Ferreira, R. R. (2013). A medicalização sob a ótica das relações de saber-poder: um olhar acerca da infância medicalizada. Monografia de Especialização, Especialização em Saúde Mental e Intervenções Psicológicas, Universidade Estadual de Maringá, Paraná.

Freud, S. (1976). Uma dificuldade no caminho da psicanálise. In J. Strachey (Ed. e J. Salomão, Trad.), Edição Standard Brasileira das Obras Psicológicas Completas de Sigmund Freud. (Vol. 17, pp. 169-182). Rio de Janeiro: Imago. (Original publicado em 1917).

Globo Comunicação e Participações S.A. (Produtor executivo). (2013, fevereiro). Os males da alma: depressão. [Programa de televisão]. Rio de Janeiro: GCP-SA. Recuperado em 17 de fevereiro de 2013, de http://g1.globo.com/fantastico/videos/t/edicoes/v/d epressao-atinge-350-milhoes-de-pessoas-nomundo/2411751/ 
Hernáez, A. M. (2010). A medicalização dos estados de ânimo: o consumo de antidepressivos e as novas biopolíticas das aflições. In S. Caponi (Org.). Medicalização da vida: ética, saúde pública e indústria farmacêutica (pp. 111-134). Palhoça: Unisul.

Institut National de Prévention et d'Éducation pour la Santé. (2007). La dépression: en savoir plus pour en sortir. France: Ministère de la Santé, de la Jeunesse et de Sports.

Instituto Sedes Sapientiae. (2013). Repúdio ao fechamento do CRIA/Carta aberta à comunidade. Recuperado em 18 de março de 2013, de http://sedes.org.br/site/node/346.

Lorenzo, C., \& Garrafa, V. (2010). Helsinque 2008: redução de proteção e maximização de interesses privados. In S. Caponi (Org.). Medicalização da vida: ética, saúde pública e indústria farmacêutica (pp. 21-35). Palhoça: Unisul.

Melman, C. (2003). O homem sem gravidade: gozar a qualquer preço. Rio de Janeiro: Companhia de Freud.

Meyer, C. (Org.). (2005) Le livre noir de la psychanalyse. Vivre, penser et aller mieux sans Freud. Paris, Éditions des Arènes.

Michaelis. (1998). Moderno dicionário da língua portuguesa. São Paulo: Companhia Melhoramentos.

Ministério da Saúde. (2011). Uso racional de antidepressivos. Recuperado em 30 de agosto de 2012 de http://portal.saude.gov.br/portal/arquivos/pdf/Tema 09-antidepressivos.pdf.

Ministério da Saúde. (2013). Depressão é parceira indesejável de $10 \%$ dos idosos. Recuperado em 20 de fevereiro de 2013 de http://portal.saude.gov.br/saude/visualizar_texto.cf m?idtxt=19108.

NIHCM Foundation. (2002). Changing patterns of pharmaceutical Innovation. Washington. Recuperado em 15 de fevereiro de 2013, de http://www.nihcm.org/pdf/innovations.pdf.

Organização Mundial de Saúde (2001). Relatório sobre a saúde no mundo 2001: saúde mental: nova concepção nova esperança. Genebra: OMS.

Onfray, M. (2010). Le crépuscule d'une idole. L'affabulation freudienne. Paris: Grasset.
Perez, D. O. (2009). A psicanálise como experiência ética e o problema da cientificidade. Revista Malestar e subjetividade, Fortaleza, 9(4), 1203-1232.

Pignarre, P. (2012). Comment la dépression est devenue une épidémie. Paris: La Découverte.

Preciado, B. (2008). Testo Yonqui. Madrid: Espasa Calpe.

Rodrigues, J. T. (2003). A medicação como única resposta: uma miragem do contemporâneo. Psicologia em Estudo 8(1), 13-22.

Roudinesco, E. (2003). A família em desordem. Rio de Janeiro: Zahar.

Roudinesco, E. (2010). Mais pourquoi tant de haine? Paris: Éditions du Seuil.

Russo, J. \& Venâncio, A. T. (2006). Classificando as pessoas e suas perturbações, a "revolução terminológica" do DSM III. Revista Latinoamericana de Psicopatologia Fundamental, 3(9), 460-483. Recuperado em 18 de janeiro de 2013 , http://redalyc.uaemex.mx/redalyc/pdf/2330/233017 487007.pdf.

Sanches, V. N. L. (2010) Estudo sobre o processo de medicalização de crianças no campo da saúde mental em um serviço de atenção básica no município do Rio de Janeiro. Dissertação de Mestrado, Programa de Pós-Graduação em Saúde Coletiva, Fundação Oswaldo Cruz, Rio de Janeiro.

Santos, R. I. \& Farias, M. R. (2010). Conflitos bioéticos e as políticas para acesso aos medicamentos. In S. Caponi (Org.). Medicalização da vida: ética, saúde pública e indústria farmacêutica (pp. 278-289). Palhoça: Unisul.

Recebido em 17/09/2013 Aceito em 19/12/2013

Letícia Vier Machado: psicóloga, mestranda no Programa de Pós-Graduação em Psicologia da Universidade Federal de Santa Catarina, bolsista CAPES.

Rodrigo Ramires Ferreira: psicólogo, mestrando no Programa de Pós-Graduação em Psicologia da Universidade Estadual de Maringá, bolsista CAPES. 